\title{
SCIDOC
}

\author{
International Journal of Dentistry and Oral Science (IJDOS) \\ ISSN: 2377-8075
}

\section{Dentists Preference Of Mode Of Teaching Brushing Technique To Children With Mixed Dentition}

Research Article

\author{
Deepthi Sogasu ${ }^{1}$, Vignesh Ravindran ${ }^{2 *}$
}

${ }^{1}$ Saveetha Dental College and Hospitals, Saveetha Institute of Medical and Technical Sciences (SIMATS), Saveetha University, Chennai- 77, India. ${ }^{2}$ Senior Lecturer, Department of Pediatric and Preventive Dentistry, Saveetha Dental College and Hospitals, Saveetha Institute of Medical and Technical Sciences [SIMATS], Saveetha University, Chennai- 77, India.

Abstract

Introduction: The main purpose of brushing is to mechanically disturb the biofilm that is formed over the tooth surface by oral bacteria. The undisturbed biofilm can become plaque, which eventually leads to caries. Thus tooth brushing is of extreme importance especially among children. Correct brushing techniques can prevent early childhood caries.

Aim: To check the preference of dentists about the mode of teaching brushing techniques to children with mixed dentition. Materials and Methods: A total of 1600 subjects with mixed dentition were chosen for this study. All the subjects were outpatients in the pediatric outpatient department of Saveetha Dental College. The data for this study was collected from DIAS and was verified using photographic confirmation and checking. All subjects were chosen randomly to minimise sampling bias. The age group considered for mixed dentition is 6 to 12 years old. The data that was obtained was tabulated in an excel spreadsheet and the analysis of the data was made using SPSS software with Chi-square test for association.

Results: From the data collected in our study, it was found that the most preferred method of teaching brushing technique is by using digital modes, followed by using casts and models and the least preferred method was only verbal explanation. There was no statistically significant difference when compared based on gender of the patient $(\mathrm{p}>0.05)$.

Conclusion: From this study, we conclude that dentists prefer using digital modes to explain and teach brushing techniques to children with mixed dentition. The purpose is to check for evolving trends in preferences in teaching. This is important so as to accommodate the increasing development of technology.

Keywords: Innovative Teaching Method; Brushing Techniques; Health Education; Pedodontics.

\section{Introduction}

The main purpose of brushing is to mechanically disturb the biofilm that is formed over the tooth surface by oral bacteria. The undisturbed biofilm can become plaque, which eventually leads to caries [1]. Thus tooth brushing is of extreme importance especially among children. Correct brushing techniques can prevent early childhood caries [2].

The best way to reduce the occurrence of plaque and caries is by using mechanical and chemical plaque controlling measures. Correct brushing technique is the most effective mechanical plaque controlling measure [3]. Regular brushing can significantly reduce the amount of plaque present on the surfaces of teeth. Due to the lack of awareness about the right methods of brushing, children brush ineffectively, preventing the removal of plaque biofilms [4].

Correct brushing requires a certain level of muscle coordination and movement, acquired at a particular stage of motor skill development. Hence assessing the kind of tooth brushing used by the child, dentists can also help identify if the child suffers from any neurological disorders [5].

Studies have shown that the brushing techniques of children below the age of 10 years are ineffective in mechanically controlling plaque biofilms [6]. Thus, dentists play an important role in correctly identifying the stage of mental dexterity in children and must use the right methods to teach effective brushing techniques

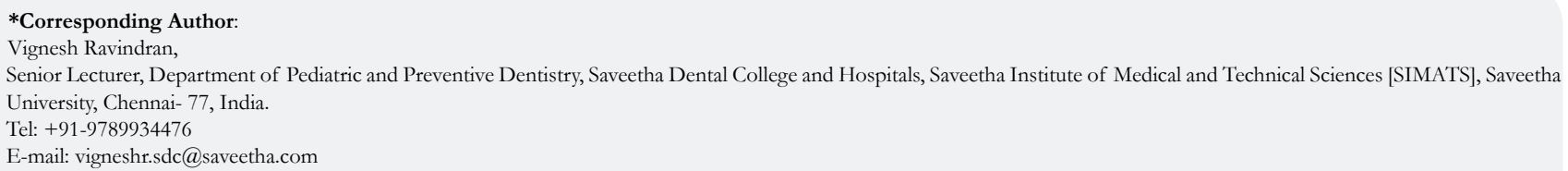

Citation: Deepthi Sogasu, Vignesh Ravindran. Dentists Preference Of Mode Of Teaching Brushing Technique To Children With Mixed Dentition. Int J Dentistry Oral Sci. 2021;8(9):4535-4538. doi: http://dx.doi.org/10.19070/2377-8075-21000923

Copyright: Vignesh Ravindran 2021 . This is an open-access article distributed under the terms of the Creative Commons Attribution License, which permits unrestricted use, distribution and reproduction in any medium, provided the original author and source are credited. 
to children. Parents mostly introduce brushing to the children; hence awareness of correct brushing techniques among parents is also important [7].

It is also important that the dentist correctly advises certain techniques of crushing over others, so as to accommodate motor dexterity of the child. It has been suggested to teach horizontal scrub and Foves technique to children below the age of 8 , and Bass method for the children above 8 years [8].

Previous studies have shown that the conventional lecture pattern of teaching children about correct brushing techniques can significantly reduce the amount of plaque on the tooth surfaces [9]. Another study conducted by Malik A et al., concluded that using crosswords as opposed to other game-based activities is more effective in teaching children about oral health and hygiene.

The necessity of this research is to identify the most preferred methods of teaching brushing techniques to children with mixed dentition. This study can help increase the awareness of various methods of teaching children. Such studies are important as the prevalence of caries among children is extremely high even though there have been so many strategies done to avoid the same. Our team has extensive knowledge and research experience that has translate into high quality publications [10-22, 23-29].

The aim of this study is to identify the preferred mode of teaching brushing technique to children with mixed dentition.

\section{Materials and Methods}

The study was done under a university setting. The Ethical approval was obtained from the Institutional ethical committee. About 2,00,000 case sheets were obtained from June 2019 to March 2020. Informed consent was obtained from the parents or guardian regarding usage of the clinical data for research purposes.

The inclusion criteria for this study consisted that the subjects had to be children within the age group of 6-12 years. The exclusion criteria consisted of subjects younger than 6 years and those older than 12 years old.

Digital entry of clinical examination, intraoral photographs of the oral cavity and the treatment procedure were assessed. The data collected (digital entry and intraoral photographs) was verified by an external additional reviewer. The subjects were chosen at random, inclusive of all genders to reduce and minimize sampling bias. If any error in data entry or patient details or clinical data were noticed, that case sheet was excluded from the study.

The data collected were tabulated in MS Excel and was then analysed in SPSS software version 22 (IBM Corp, Texas, LA). The independent variables of this study were gender and geographic background. The dependent variables were the age of the patient and mode of teaching brushing technique. Descriptive statistics were used and comparison between groups were done by using Chi square tests.

\section{Results}

A total of 1600 subjects were considered for this study. Majority of the subjects in the study were male $(55.7 \%)$ were as female patients consisted of $44.3 \%$ of the sample population (Graph 1). Majority of the dentists preferred digital mode for teaching children $(60.4 \%)$ followed by cast and model method $(22.4 \%)$ and verbal only (17.3\%) (Graph 2). There was no difference in mode of teaching brushing technique based on gender of the patient (Pearson chi-square test, $\mathrm{p}$-value $=0.97$ - not statistically significant) (Graph 3).

Graph 1: Bar chart representing percentage distribution (\%) of male and female subjects who participated in the study. The $\mathrm{X}$ axis represents the gender and the $\mathrm{Y}$ axis represents the percentage distribution among each gender. Majority of the subjects in the study were male $(55.7 \%)$ were as female patients consisted of $44.3 \%$ of the sample population. Blue represents male population and orange represents female population.

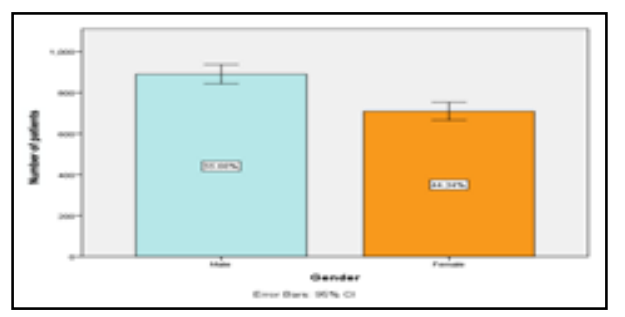

Graph 2: bar chart representing the percentage distribution (\%) for the different modes of teaching preferred by dentists for teaching children with mixed dentition about correct brushing techniques. The $\mathbf{X}$ axis represents the various modes of teaching and the $\mathrm{Y}$ axis represents the percentage distribution for each mode of teaching respectively. Majority of the dentists preferred digital mode for teaching children (60.4\%-blue) followed by cast and model method (22.4\%-green) and verbal only (17.3\%-beige).

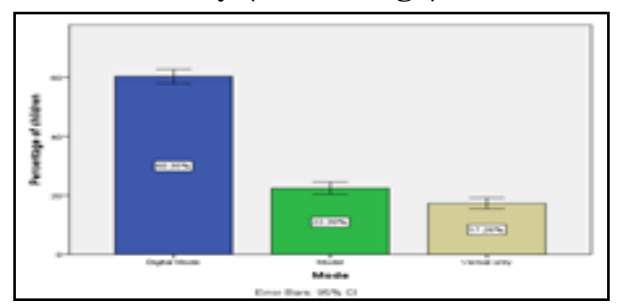


Graph 3: Bar graph representing comparison between gender and which mode of teaching brushing technique was preferred. The $X$ axis represents gender and the $Y$ axis represents the mode of teaching preferred. Blue color represents digital mode of teaching, green colour represents use of casts and models and brown colour represents use of only verbal modes of teaching. From the graph, we can conclude that there was no difference in mode of teaching brushing technique based on gender of the patient (Pearson chi-square test, p-value $=0.97$ - not statistically significant).

\section{Discussion}

The results from this study proved that dentists prefer using digital audiovisual mode of educating patients rather than using casts or verbally explaining brushing techniques. The results obtained in graph 1 suggest that the majority of the subjects in the study were male $(55.7 \%)$ and females made up $(44.3 \%)$ of the remaining sample population. A study conducted in 1999 suggests that male prevalence was slightly higher compared to females on comparing the gender prevalence of paediatric patients using clinics. All other recent studies deliberately included an equal number of males and female participants in their study. Thus, in a randomised sample population, male predominance is seen which supports our finding from this study.

On analysing the results from graph 2, we can confirm that digital or audiovisual mode of teaching brushing techniques to children was mostly preferred by dentists $(60.4 \%)$, followed by the used of cast and models $(22.4 \%)$ and finally, the use of verbal cues only $(17.3 \%)$. A study conducted in 2012 compared digital and manual modes of teaching brushing techniques. The authorities concluded that the digital method - ROBOTUTOR was easier to use and more time efficient [30]. Another similar study by Leal et al suggested that audiovisual modes of teaching brushing techniques to children was more commonly preferred [6]. On the contrary, in the study by Malik A et al., they suggested that using a game based approach such as crosswords is a good way to reinforce oral hygiene habits to children [31]. Considering precious literature, the most common mode of teaching brushing techniques used include some form of audiovisual or digital methods. This confirms our findings from the study.

The results inferred from graph 3 is that the audiovisual code was more commonly preferred for both male and female children with mixed dentition. Preference of mode of teaching does not depend on gender of the patient. Some studies by child psychologists suggest that boys and girls have different perceptions about learning and hence must be educated in prompt ways [32]. On the whole, in a dental set up, gender does not influence the mode of teaching selected for educating children about the correct brushing techniques. It is found that good plaque control is achieved in both males and females after audiovisual aids were used to teach brushing techniques [6].

Instilling the correct brushing techniques from a young age is imperative to maintaining good oral health. With age, multiple problems arise as a consequence of incorrect brushing methods.
Correct and appropriate reinforcement of brushing techniques among children with mixed dentition is of utmost importance, concerning the dentist. There are multiple methods to teach brushing techniques to children. From the results obtained from our study, the most common and preferred method used for teaching children the various brushing techniques is using digital or audiovisual methods followed by use of casts and models and only verbal means of communication. Other studies have also concluded by mentioning greater credits and preference to digital modes of teaching brushing techniques, hence reinforcing our findings in this study. The purpose of this study is to increase the awareness of the different possibilities in teaching children different brushing techniques. It also analyses the most preferred, time efficient method of teaching the same, i.e. digital means of teaching brushing techniques. Although the choice of teaching method depends on the comfort of the dentist and the patient.

The main advantage of conducting the study in a university setting is that it aids as a single center for multiple people from different localities at the same time. The main limitation of this study is the unicentric nature of the topic. The results obtained have low external validity and are not diversified. The reason for this could be because of small sample size and male predominance within the sample population. Inclusion of more teaching methods also could have diversified the results.

The future scope of the study is that it can accommodate the changing trends of teaching and learning patterns among children with the increasing advancements in technology.

\section{Conclusion}

Thus, within the limits of the study, digital or audiovisual mode of teaching brushing techniques to children with mixed dentition was preferred by dentists. Preference did not change in relation to the gender of the patient.

\section{Acknowledgement}

The authors are thankful to the Department of Pediatric Dentistry, Saveetha Dental College, Saveetha Institute of Medical and Technical science, Saveetha University for providing a platform in expressing their knowledge.

\section{Source of Funding}

The present project was funded by 
- Saveetha Dental College,

- Saveetha Institute of Medical and Technical Sciences,

- Saveetha University and

- Sharmila Arts, Bangalore

\section{References}

[1]. Aljerf L, Al Masri N. In Vitro Investigated Study of the Relationship among Fluoride of Plaque and Caries. EC Dent Sci. 2018;17:892-9.

[2]. Boustedt K, Dahlgren J, Twetman S, Roswall J. Tooth brushing habits and prevalence of early childhood caries: a prospective cohort study. Eur Arch Paediatr Dent. 2020 Feb;21(1):155-9.

[3]. Okada M, Kuwahara S, Kaihara Y, Ishidori H, Kawamura M, Miura K, et al. Relationship between gingival health and dental caries in children aged 7-12 years. J Oral Sci. 2000 Sep;42(3):151-5.Pubmed PMID: 11111326.

[4]. Deinzer R, Cordes O, Weber J, Hassebrauck L, Weik U, Krämer N, et al. Toothbrushing behavior in children-an observational study of toothbrushing performance in 12 year olds. BMC oral health. 2019 Dec;19(1):68.

[5]. Mafla AC, Benavides RJ, Giraudeau N, Meyer P. Toothbrushing Patterns as Indicator of Neurodevelopment in Children. iadr.abstractarchives.com.

[6]. Leal SC, Bezerra AC, Toledo OA. Effectiveness of teaching methods for toothbrushing in preschool children. Braz Dent J. 2002;13(2):133-6.

[7]. Srivastava N, Gupta G, Rana V. A comparative evaluation of efficacy of different teaching methods of tooth brushing in children contributors. Journal of Oral Hygiene \& Health. 2013 Dec 25;1(3):1-4.

[8]. Atarbashi-Moghadam F, Atarbashi-Moghadam S. Tooth brushing in children. J. dent. mater. tech. 2018;7(4):181-4.

[9]. Stein C, Santos NML, Hilgert JB, Hugo FN. Effectiveness of oral health education on oral hygiene and dental caries in schoolchildren: Systematic review and meta-analysis. Community Dent Oral Epidemiol. 2018 Feb;46(1):30-37.Pubmed PMID: 28815661.

[10]. Subramanyam D, Gurunathan D, Gaayathri R, Vishnu Priya V. Comparative evaluation of salivary malondialdehyde levels as a marker of lipid peroxidation in early childhood caries. Eur J Dent. 2018 Jan-Mar;12(1):67-70. Pubmed PMID: 29657527.

[11]. Ramadurai N, Gurunathan D, Samuel AV, Subramanian E, Rodrigues SJ. Effectiveness of $2 \%$ Articaine as an anesthetic agent in children: randomized controlled trial. Clin Oral Investig. 2019 Sep;23(9):3543-50.

[12]. Ramakrishnan M, Dhanalakshmi R, Subramanian EMG. Survival rate of different fixed posterior space maintainers used in Paediatric Dentistry - A systematic review. Saudi Dent J. 2019 Apr;31(2):165-172.Pubmed PMID: 30983825.

[13]. Jeevanandan G, Thomas E. Volumetric analysis of hand, reciprocating and rotary instrumentation techniques in primary molars using spiral computed tomography: An in vitro comparative study. Eur J Dent. 2018 JanMar;12(1):21-26.Pubmed PMID: 29657521.

[14]. Princeton B, Santhakumar P, Prathap L. Awareness on Preventive Measures taken by Health Care Professionals Attending COVID-19 Patients among Dental Students. Eur J Dent. 2020 Dec;14(S 01):S105-S109.Pubmed PMID: 33321549

[15]. Saravanakumar K, Park S, Mariadoss AVA, Sathiyaseelan A, Veeraraghavan VP, Kim S, et al. Chemical composition, antioxidant, and anti-diabetic activities of ethyl acetate fraction of Stachys riederi var. japonica (Miq.) in streptozotocin-induced type 2 diabetic mice. Food Chem Toxicol. 2021 Sep;155:112374.Pubmed PMID: 34186120.

[16]. Wei W, Li R, Liu Q, Seshadri VD, Veeraraghavan VP, Mohan SK, et al. Amelioration of oxidative stress, inflammation and tumor promotion by Tin oxide-Sodium alginate-Polyethylene glycol-Allyl isothiocyanate nanocomposites on the 1,2-Dimethylhydrazine induced colon carcinogenesis in rats. Arab. J. Chem. 2021 Jun 3;14(8):103238.
[17]. Gothandam K, Ganesan VS, Ayyasamy T, Ramalingam S. Antioxidant potential of theaflavin ameliorates the activities of key enzymes of glucose metabolism in high fat diet and streptozotocin - induced diabetic rats. Redox Rep. 2019 Dec;24(1):41-50.Pubmed PMID: 31142215.

[18]. Su P, Veeraraghavan VP, Krishna Mohan S, Lu W. A ginger derivative, zingerone-a phenolic compound-induces ROS-mediated apoptosis in colon cancer cells (HCT-116). J Biochem Mol Toxicol. 2019 Dec;33(12):e22403. Pubmed PMID: 31714660.

[19]. Mathew MG, Samuel SR, Soni AJ, Roopa KB. Evaluation of adhesion of Streptococcus mutans, plaque accumulation on zirconia and stainless steel crowns, and surrounding gingival inflammation in primary molars: randomized controlled trial. Clin Oral Investig. 2020 Sep;24(9):3275-3280.Pubmed PMID: 31955271.

[20]. Sekar D, Johnson J, Biruntha M, Lakhmanan G, Gurunathan D, Ross K. Biological and clinical relevance of microRNAs in mitochondrial diseases/ dysfunctions. DNA Cell Biol. 2020 Aug 1;39(8):1379-84.

[21]. Velusamy R, Sakthinathan G, Vignesh R, Kumarasamy A, Sathishkumar D, Priya KN, et al. Tribological and thermal characterization of electron beam physical vapor deposited single layer thin film for TBC application. Surf Topogr: Metrol Prop. 2021 Jun 24;9(2):025043.

[22]. Aldhuwayhi S, Mallineni SK, Sakhamuri S, Thakare AA, Mallineni S, Sajja R, et al. Covid-19 Knowledge and Perceptions Among Dental Specialists: A Cross-Sectional Online Questionnaire Survey. Risk Manag Healthc Policy. 2021 Jul 7;14:2851-2861.Pubmed PMID: 34262372.

[23]. Sekar D, Nallaswamy D, Lakshmanan G. Decoding the functional role of long noncoding RNAs (lncRNAs) in hypertension progression. Hypertens Res. 2020 Jul;43(7):724-725.Pubmed PMID: 32235913.

[24]. Bai L, Li J, Panagal M, M B, Sekar D. Methylation dependent microRNA $1285-5$ p and sterol carrier proteins 2 in type 2 diabetes mellitus. Artif Cells Nanomed Biotechnol. 2019 Dec;47(1):3417-3422.Pubmed PMID: 31407919.

[25]. Sekar D. Circular RNA: a new biomarker for different types of hypertension. Hypertens Res. 2019 Nov;42(11):1824-5.

[26]. Sekar D, Mani P, Biruntha M, Sivagurunathan P, Karthigeyan M. Dissecting the functional role of microRNA 21 in osteosarcoma. Cancer Gene Ther. 2019 Jul;26(7-8):179-182.Pubmed PMID: 30905966.

[27]. Duraisamy R, Krishnan CS, Ramasubramanian H, Sampathkumar J, Mariappan S, Navarasampatti Sivaprakasam A. Compatibility of Nonoriginal Abutments With Implants: Evaluation of Microgap at the Implant-Abutment Interface, With Original and Nonoriginal Abutments. Implant Dent. 2019 Jun;28(3):289-295.Pubmed PMID: 31124826.

[28]. Parimelazhagan R, Umapathy D, Sivakamasundari IR, Sethupathy S, Ali D, Kunka Mohanram R, et al. Association between Tumor Prognosis Marker Visfatin and Proinflammatory Cytokines in Hypertensive Patients. Biomed Res Int. 2021 Mar 16;2021:8568926.Pubmed PMID: 33816632.

[29]. Syed MH, Gnanakkan A, Pitchiah S. Exploration of acute toxicity, analgesic, anti-inflammatory, and anti-pyretic activities of the black tunicate, Phallusia nigra (Savigny, 1816) using mice model. Environ Sci Pollut Res Int. 2021 Feb;28(5):5809-5821.Pubmed PMID: 32978735.

[30]. Ahire M, Dani N, Muttha R. Dental health education through the brushing ROBOTUTOR: A new learning experience. J Indian Soc Periodontol. 2012 Jul;16(3):417-20.Pubmed PMID: 23162339.

[31]. Malik A, Sabharwal S, Kumar A, Singh Samant P, Singh A, Kumar Pandey V. Implementation of Game-based Oral Health Education vs Conventional Oral Health Education on Children's Oral Health-related Knowledge and Oral Hygiene Status. Int J Clin Pediatr Dent. 2017 Jul-Sep;10(3):257-260. Pubmed PMID: 29104385.

[32]. Darling-Hammond L, Flook L, Cook-Harvey C, Barron B, Osher D. Implications for educational practice of the science of learning and development. Appl Dev Sci. 2020 Apr 2;24(2):97-140. 